NBER WORKING PAPER SERIES

\begin{abstract}
A POUND OF FLESH OR JUST PROXY?
USING TWIN DIFFERENCES TO ESTIMATE

THE EFFECT OF BIRTH WEIGHT ON LIFE CHANCES
\end{abstract}

\author{
Dalton Conley \\ Kate Strully \\ Neil G. Bennett \\ Working Paper 9901 \\ http://www.nber.org/papers/w9901 \\ NATIONAL BUREAU OF ECONOMIC RESEARCH \\ 1050 Massachusetts Avenue \\ Cambridge, MA 02138 \\ August 2003
}

The views expressed herein are those of the authors and not necessarily those of the National Bureau of Economic Research.

(C)2003 by Dalton Conley, Kate Strully, and Neil G. Bennett. All rights reserved. Short sections of text, not to exceed two paragraphs, may be quoted without explicit permission provided that full credit, including (C) notice, is given to the source. 
A Pound of Flesh or Just Proxy? Using Twin Differences to Estimate

the Effect of Birth Weight on Life Chances

Dalton Conley, Kate Strully, and Neil G. Bennet

NBER Working Paper No. 9901

August 2003

JEL No. I12

$\underline{\text { ABSTRACT }}$

Recent research into the implications of low birth weight may be plagued by unobserved variable bias. It is unclear whether the later-life consequences found to be associated with low birth weight are a true effect of "poundage" at birth, or whether this association results from underlying factors related to birth weight - such as genetics, gestational age, pregnancy-related behavior, or prenatal environment. In this study, we employ twin comparisons to rule out such unobserved factors and to isolate more precise effects of birth weight on infant mortality. Using data from the 1995-1997 Matched Multiple Birth Database and deducing zygosity based on the sex ratio of twin births, we examine the effects of birth weight for both fraternal and identical twins on both neonatal and post-neonatal mortality. Results suggest that in the neonatal period, low birth weight may partially be acting as a proxy for underlying genetic conditions, but in the post-neonatal period birth weight per se increases the risk of mortality. Thus, it appears that after an initial "weeding-out" period in which the more severe ailments associated with genetics may be behind birth weight effects, "poundage" itself has a significant impact on life chances net of genes and other pregnancyspecific health or social conditions.

Dalton Conley

NYU

269 Mercer Street $4^{\text {th }}$ Floor

New York, NY 10003

and NBER

dalton.conley@nyu.edu

Neil G. Bennett

Baruch School of Public Affairs and Graduate Center

City University of New York

17 Lexington Avenue

New York, NY 10010

and NBER

neil_bennett@baruch.cuny.edu
Kate Strully

NYU Sociology 


\section{A Pound of Flesh or Just Proxy? Using Twin Differences to Estimate the Effect of Birth Weight on Life Chances}

\section{BACKGROUND}

Recent research by Conley and Bennett $(2000,2001)$ uses sibling comparisons to reveal a strong association between weight at birth and educational attainment at age 19. Specifically, these authors find that a low birth weight sibling is 74 percent less likely than a normal birth weight sibling to complete high school by 19 years of age. The sibling fixed-effect framework used by Conley and Bennett provides several advantages over the traditional, across-family models used by other researchers in this area (Hack et al. 2002; Rich-Edwards 1997; Sorensen et al. 1997) because it can factor out significant amounts of the unobserved variation in familial, environmental, and biological conditions that may lead to spurious low birth weight effects.

Nonetheless, unobserved variation in the causes and consequences of low birth weight remain an issue in this work, limiting Conley's and Bennett's ability to make strong causal statements about the effects of birth weight. Low birth weight may reflect various conditionsranging from intrauterine growth retardation (IUGR) to preterm delivery to genetic predispositions - each of which may be associated with pregnancy-specific social, behavioral, and biological conditions. None of these different etiologies can be isolated or ruled out with sibling comparisons, and all of them may conceivably have different long-term implications. That is, there is no way to tell whether those low birth weight siblings in Conley's and Bennett's sample who did not graduate by age 19 were born small because of growth retardation, preterm delivery, a genetic tendency toward low birth weight, or because of pregnancy-specific environmental or social conditions. It is, therefore, unclear whether the educational outcomes 
documented by Conley and Bennett represent true effects of weight at birth or whether this measure of infant size is acting as a proxy for other underlying social or biological conditions.

In this study, we address this ambiguity, considering whether it is a "pound of flesh" that really matters or whether it is other, pregnancy-specific conditions associated with birth weight that ultimately matter. We use twin births from the 1995-1997 Matched Multiple Birth Database to hold constant the unobserved etiological factors that plague existing analyses and to isolate the specific effects of birth weight (i.e., fetal growth) on infant mortality. Because twins share the same pregnancy, unobserved variation in prenatal environment (i.e., exposure to toxins, poverty, or other social stressors) and in parental behavior (i.e., smoking, drinking, or diet), which may be associated with birth weight and which may vary between siblings' births can be eliminated. Further, examining twins addresses the confounding of the two main causes of low birth weight - preterm delivery and intrauterine growth retardation (IUGR, also known as small for gestational age [SGA]). While most twins do not go the full 40 weeks gestation that is the norm for singleton births (and many do not make the 37 week cut-off for "maturity" status), the fact remains that they are generally born at the same time plus or minus a matter of minutes or hours. Thus, birth weight differences between twins in this study will reflect growth differences, and the alternative cause of preterm delivery (with gestationally-appropriate growth) will be held constant. Evidence suggests that preterm delivery and IUGR can result from different conditions. Kallan (1993), for instance, found that variation in IUGR is more sensitive to socio-demographic and behavioral factors, while variation in preterm delivery is more sensitive to biological conditions (such as hypertension or infections). Further, evidence suggests that preterm birth status is more strongly associated with infant mortality than IUGR (for a discussion of this evidence see Frisbie et al. 1996). Thus, separating out these two central causes of infant size can 
be quite important to understanding why low birth weight might matter in both the short-term and the long-run.

Finally, separating out the effect of birth weight differences for fraternal twins from that for identical twins gives us some purchase on the role of birth weight as a proxy for the genetic "robustness" of the infant. The siblings used by Conley and Bennett share — on average — only about 50 percent of their genes, so spuriousness from genetic variation remains an issue. ${ }^{1}$ That is, siblings' birth weight differences could be a result of innate genetic differences, which may, in turn, be causally implicated in later educational outcomes as well. In this study, however, we can compare twins that share 100 percent of their genes, eliminating the possibility that birth weight reflects underlying genetic tendencies.

The 1995-1997 Matched Multiple Birth Database provides a unique opportunity to analyze almost all identical and fraternal twin births and deaths within a two-year period (because this dataset is based on national Vital Statistics it contains records for most births and infant deaths within the specified years). Yet, this dataset does not allow us to employ the same outcome measure as Conley and Bennett. Having been born in the years 1995 to 1997, these twin sets have no educational record to speak of. Therefore, we use infant morality as our outcome, with the assumption that the same risks that would predict infant death also would predict poor developmental outcomes among the survivors. To bolster this assumption, we consider the effects of birth weight on both neonatal and post-neonatal mortality. Examining the differences in the effects of birth weight by zygosity on these two mortality time frames opens a window for understanding what type of biases emerge or disappear as one moves farther from the starting gate of life. (See discussion below on this analytic strategy.)

\footnotetext{
${ }^{1}$ Due to positive or negative assortative mating, singleton siblings and fraternal twins may share more or less than 50 percent of their genes.
} 


\section{Previous Use of Twin Difference Estimates}

While twin comparisons are relatively uncommon in research on infant mortality, this method has a considerable legacy in research on the returns to schooling. Since identical twins share the same genetic endowments and are generally raised in similar environments, it has often been assumed that systematic, unobserved variation is negligible in these cases and estimates of educational returns based on twin comparisons will reflect true effects. ${ }^{2}$

However, some authors, such as Bound and Solon (1998), have not been so optimistic and suggest to the contrary that such unobserved heterogeneity does exist, causing significant problems for twin comparisons. According to Bound and Solon, even though the unobserved differences between twins may be very small, they still may be strongly associated with both education and wages and, therefore, may still bias (likely in an upward direction) twin-based estimates of the returns to education. Because of such endogenous heterogeneity, these authors conclude that, "it is unclear whether the covariance estimator based on between-twins variation is subject to less inconsistency than the conventional OLS estimator" (1998: 14). This inconsistency in twin comparisons can become compounded if measurement error is taken to be regressive to the mean, as opposed to randomly distributed as in the classic errors-in-variables case (ibid).

This sort of endogenous heterogeneity among twins, however, is likely not a concern in our analysis of birth weight and infant mortality. Because we are dealing with infants, particular tastes or motivation are not likely to be salient issues. While systematic variation in social

\footnotetext{
${ }^{2}$ Ashenfelter and Rouse (1997), for example, assume that differences in the educational attainment of identical twins in the same family "result from either measurement error or random deviations from the optimum schooling level." In other words, variation in the level of schooling
} 
environments may emerge as twins age_-entering different schools or classrooms or making different friends - environmental variation during infancy will likely be quite minimal, provided that twins reside in the same household (which will most likely be the case). In an industrialized nation with a low infant mortality rate like the United States, it is also rather unlikely that parents' behavior will significantly bias twin comparisons of infant morality. In a nation with considerably fewer resources and a higher incidence of infant mortality it may be more likely that we would witness systematic bias in the allocation of resources toward the larger or stronger twin within a pair, which could lead to spurious birth weight effects. If such factors were at work, it could be the case that the smaller twin is neglected and left to "make it or not" on his or her own through a process of natural selection. Behind such a tendency could be psychological mechanisms. As an example, smaller size could signal mortality risk to a parent, causing the parent not to bond with the child for fear of losing him/her (see, e.g., Scheper-Hughes 1992). In cases where such selective or protective strategies are at play, it might be the case that the source of birth weight related differences in mortality rates between twins is an endogenous artifact of parental (or societal) behavior. But, in the United States such bias will likely not take place on a wide enough scale to create spurious (or even inflated) associations between birth weight and infant mortality. In fact, it may be reasonable to assume that in the context of an industrialized nation with a relatively low infant mortality rate-like the United States_more resources and attention would be given to the high risk (i.e., lower weight) twin, and thus our estimates of the impact of birth weight on survival would be biased downward (as compared to those that would be associated with equal treatment of the two twins).

Our analysis is further distinguished from other research on twin differences because we

between twins should be exogenous and random [or at least unrelated to the outcomes that schooling is said to predict] and therefore should not affect estimates of educational returns. 
look at both fraternal and identical twin sets. This difference allows us to rule out underlying genetic variation without making large sacrifices in the generalizability of our results. By contrast, Behrman and Rosenzweig (2001), for example, use differences in birth weight among identical twins from the Swedish National Twin Registry to estimate the schooling returns to fetal growth. Regressing twin differences in schooling against twin differences in birth weight, these researchers find that each additional pound is associated with almost a third of year more of schooling. This finding is based, however, on a data set of only identical twins so a question remains open: Are the effects of birth weight differences between identical twins overstated when generalized to the entire population?

Imagine that each child in the world has a genetically "optimal" birth weight. For one child this may be six pounds and for another it may be seven pounds. Within some acceptable range, let us imagine that each child attained this weight. For child one, six pounds represents full development, and for child two there is an extra pound of flesh, but this really does not reflect more consequential fetal development. Rather, it reflects a genetic tendency. In this case, there may be no real effect of that pound difference in birth weight — each child is at his or her ideal weight. However, compare this to the situation of identical twins, where we know that - by definition - the ideal birth weight for each is the same. In this case, where there is genetic consistency along with competition for nutrients and space, a birth weight difference necessarily means that one (or more likely both) twin(s) is/are not reaching their genetically "ideal" weight. Fraternal twin differences in weight are also frequently due to the competition between the fetuses for resources and the random event of who is in better position within the placenta. However, with fraternal twins, size differences can also be the result of variation in genetically "ideal" weights. If such causes of birth weight further mean that birth weight can have 
consequences of varying severity, then we may run into problems of generalizability. Most notably, if genetic differences in birth weight have less severe implications than differences resulting from prenatal competition, then generalizing from identical twins to fraternal twins or to singleton births may lead to an overstatement of the effects of birth weight.

Non-genetic aspects of twinning biology may also mean that results from identical twins are not generalizable to larger populations. All fraternal twins are dichorionic - meaning that they each have their own placenta. The majority of identical twins (it has been estimated between 64 and 85 percent of white twins), however, are monochorionic - meaning that they share a placenta. The remaining portion of identical twins will be dichorionic and, like fraternal twins, will each have their own placenta (Burn et al. 1988). Sharing a placenta has been shown to significantly increase the risk of adverse outcomes in twin pregnancies. Because twins in one placenta will be connected to one another via the placenta, the tendency for unequal sharing the placenta and for competition leading to growth discordance is significantly increased for monochorionic twins compared to dichorionic twins (Dube et al. 2002). Thus, a smaller genetically identical twin may be significantly more nutritionally deprived than a comparable fraternal twin or singleton birth, and therefore size in this case may represent a higher risk than size in other cases. Across identical and fraternal twin sets, competition for nutrients or space and genetic variation will play varying roles in birth weight differences, and to the degree that these different etiologies are associated with different consequences of birth weight, results from identical twins may not be generalizable to other groups.

Considering both identical and fraternal twin pairs, however, we can begin to address this possibility in this study. For instance, if we find that the impact of birth weight differences on the twin-specific risk for death is stronger for identical twins than that for fraternal twins, we 
could conclude that birth weight differences among twins resulting from sibling rivalry for nutrients are really much more salient than those that result from underlying genetic differences. In other words, such a result suggests that nutritional deprivation could be what really matters. In this case, we could conclude that it is dangerous to generalize from an identical twin population to all babies since we know that this particularly harmful cause of low birth weight — nutritional risk - is much greater on average among the twin sets. It is precisely this possibility that Behrman and Rosenzweig cannot rule out. If we generalized in this case, it would translate to sounding the alarms for that one-pound difference between the six-pound and the seven-pound baby when it really does not matter since they are each at their genetically ideal weight. Alternatively, if our results suggest that the effect of birth weight differences is stronger for fraternal twins than for identical twins, we would be led, in contrast, to the conclusion that underlying genetic differences are more detrimental than twin-specific competition. This finding would suggest that existing estimates of birth weight effects based on singleton births are biased upward because of genetic variation. In short, by comparing both identical and fraternal twins in this study we can rule out genetic variation to assess the true effect of fetal growth, but we can also assess the generalizability of these results beyond the unique case of identical twins by considering how results vary across identical and fraternal twin comparisons.

Ultimately, however, examining the effects of twins' birth weight differences by zygosity on both neonatal and post-neonatal mortality will offer the important opportunity for considering the types of biases that emerge or disappear when researching the role of infant health across the life course. That is, considering two different time periods, we can examine how the possibility of genetic spuriousness increases or decreases as time passes. For example, if for neonatal mortality the effects of birth weight are the same for fraternal and identical twins, but for post- 
neonatal mortality birth weight seems to matter only for fraternal twins, then it would appear that after an initial "weeding out" selection process, any lingering effects of birth weight are really reflective of underlying genetic differences. This possibility would suggest that Conley's and Bennett's (2000) results for birth weight on education 19 years out from birth are largely reflecting underlying differences among the children and do not accurately capture the effects of poundage per se. However, the opposite dynamic could hold. Namely, envision the scenario in which the effect of birth weight is more severe for fraternal twins in the first stage of life (neonatal mortality) but then as we progress outward from the starting gate, the effect of birth weight equalizes for fraternal and identical twins. This would suggest that early in life - during that weeding out process - birth weight may often be acting as a proxy for congenital differences, but any longer-term consequences are related to the weight itself. Of course, our analysis could show that the further we move from the starting gate, the effects diminish entirely for both groups.

\section{Twins, Birth Weight, and Infant Mortality}

As this discussion of generalizability suggests, twin pregnancies are unique and often suffer from complications. Consequently, twin pairs face significantly higher rates of adverse birth outcomes than singleton births. While only 1.09 and 6.05 percent of singleton births between 1995 and 1997 were very low birth weight and low birth weight, respectively, 10.2 and 53.4 percent of twins that same period were very low birth weight and low birth weight, respectively (Martin et al. 1999). This higher risk of low birth weight among twins is in turn an important factor in an individual twin's risk of infant mortality. According to one study, for every 250 gram increase in birth weight, a twin's risk of mortality falls by about 40 percent 
(Fraser et al. 1994). (This study does not look at twin differences, however, and therefore is subject to the same problem of unobserved heterogeneity that studies of singleton births are.) Further, because twins are sharing the same pregnancy, risk is often linked to pair-specific characteristics as well. As we discussed above, competition among twins for nutrients and space means that substantial differences in birth weights are quite common among twins, and current evidence suggests that a birth weight discordance of 30 percent or higher marks a significant threshold in the threat on birth outcomes. That is, once one twin is about a third smaller than the other, there is a marked increase in the mortality risk faced by the twin pair (Hollier et al. 1999; Cheung et al. 1995; Yalcin et al. 1998). ${ }^{3}$

However, the exact relationship between such pair-specific risk and a twin's individuallevel risk remains somewhat unclear. Given that low birth weight has a negative effect on an individual twin's infant health in traditional, across-family comparisons, we would expect to consistently find that the smaller twin in a twin pair is at a higher risk than his or her larger counterpart. Previous results regarding this question, however, are not consistent. Some studies have found no difference by size in the risk of morbidity (i.e., respiratory distress, intensive care admissions, seizures, etc.) or risk of mortality (i.e., fetal death and neonatal death) faced by each twin in a given pair (Talbot et al. 1998; Hollier et al. 1999; Almond et al. 2002). One very notable study by Almond, Chay, and Lee (2002) uses twin differencing techniques and data based on matched Vital Statistics records to document a negligible effect of birth weight on infant mortality. The findings of this study suggest that once one uses twin comparisons to hold constant various sources of unobserved variation, the effect of birth weight on infant mortality is largely eliminated.

\footnotetext{
${ }^{3}$ Existing evidence suggests, however, that only about four percent of twin pairs exhibit such large discordance (see Hollier et al. 1999).
} 
Other studies, however, that do not necessarily use twin differencing techniques or as representative data, have found some evidence to suggest that birth weight effects for twins may depend on additional factors like amount of discordancy and gestational age. One study, for instance, found that the smaller infant in a twin pair faces a significantly higher risk of infant death when discordance reaches 30 percent or higher (Cheung et al. 1995). Still another study found that there was no difference in respiratory distress between smaller and larger twins in twin pairs, until gestation reaches 28 weeks or more, at which point the heavier twin was more likely to need a respirator at four hours of age (although these authors caution that size appears to be less of a risk factor to respiratory distress than birth order and sex) (Webb and Shaw 2001). There is some evidence to suggest that this ambiguity around twins' birth weight and risk has to do with gestational age. Twins with sizable discordance in growth rates represent a subsample of very high risk pregnancies. This implies that in many cases growth rate discordance is associated with preterm delivery (both spontaneous and induced). According to one study, physicians will often induce preterm labor in highly discordant twin pairs in order to reduce the risk of fetal death of the smaller twin, but this tendency leads to alternative complications for the twin pair resulting from prematurity (Hollier et al. 1999). In short, because twins who are highly discordant are more likely to be delivered preterm, they face an increased risk of complications resulting from prematurity, which are less likely to distinguish between size. That is, because both twins may be suffering from prematurity in some twin pairs with highly discordant birth weight, the implications of size difference may be overwhelmed by the implications of gestational age. $^{4}$

\footnotetext{
${ }^{4}$ The above cited studies draw on a range of data with varying degrees of representativeness: Webb and Shaw (2001) use a retrospective study of twin pairs under 36 weeks gestation admitted to a regional neonatal unit over a three-year period. Cheung et al. (1995) study 122 live born twin sets delivered between 25 and 34 completed weeks gestation. Hollier et al. (1999) study 1370 consecutive women who delivered at Parkland Hospital in Texas
} 
It should be noted that none of the above studies take zygosity into account. Thus, there could be unaccounted for genetic factors that are reducing the implications of birth weight for twins' outcomes in discordant pairs. As we discussed above, if one twin is smaller because of a genetic tendency in a fraternal twin pair, then this may be less harmful than IUGR resulting from competition for nutrients, which will be the only cause of discordance in a genetically identical twin pair. Similarly, the issue of chorionicity discussed above could be confounding these estimates. Chorionicity may also mean that small size indicates higher risk for identical twins (many of whom may be sharing a placenta) than for fraternal twins (none of whom will be sharing a placenta) so that estimates of the effects of birth weight are again confounded by unobserved differences in the specific causes of birth weight.

\section{RESEARCH STRATEGY}

\section{Sample}

The Matched Multiple Birth Data Set 1995-1997 provides researchers with a unique opportunity to examine a population, rather than a sample. Because the Matched Multiple Birth Data Set was created using Vital Statistics maintained by the National Center for Health Statistics it contains records for almost all multiple births and infant deaths is the selected years. ${ }^{5}$ This data set was created by combining the restricted-use U.S. Live Birth and Fetal Death files for 1995-1997 with the Linked Live Birth/Infant Death Cohort Data Sets for 1995-1997.

In creating the dataset, members of twin and triplet birth sets were first identified by matching records within the U.S. Live Birth and Fetal Death files for 1995-1997. This new file

between January 1, 1996, and December 31, 1996. Talbot et al. (1997) have a retrospective study of hospital records of twins delivered between January 1, 1988 and June 30, 1995. Almond, Chay, and Lee (2002) use the population of twin births and infant deaths in 1989 for their analysis. 
of multiple birth sets was then matched with the Linked Live Birth/Infant Death Cohort Data

Sets for 1995-1997 in order to identify infant deaths that corresponded to the live twin and triplet birth records (for a further discussion of the different algorithms used in various stages of matching see Martin et al. 1998). This matching process was quite successful; approximately 98 percent of records were matched (out of the 324,490 twins and triplets born during the selected years, 320,534 were matched) (NCHS 1998). In this study, we restrict our analysis to twin pairs who were both born alive and who have valid information on all of the variables in our analysis. ${ }^{6}$ This yields a total sample size of 271,998 . For descriptive statistics of this sample, by discordance and sex, see Table 1, below.

\section{[TABLE ONE ABOUT HERE]}

\section{Analytic Approach}

While the Matched Multiple Birth Data Set contains several variables ranging from number of prenatal visits to specific causes of death, it does not have data on zygosity. That is, we do not know whether twin pairs are identical or fraternal. We are able to deduce this information, however, by breaking down our sample by sex.

In this approach we are following the hypothesis originally proposed by Weinberg (1902). Weinberg proposed that twins are equally like to be male as to be female ${ }^{7}$ and

\footnotetext{
${ }^{5}$ A handful of cases could not be matched and therefore are not included in the dataset.

${ }^{6}$ It could be the case that the omission of fetal deaths from consideration biases our results. At the extreme, for example, we might posit that all future low birth weight babies of one twin type or another are "weeded out" as fetal deaths. If this were the case, the interpretation of our models would be problematic. To address this possibility, we also analyzed a sample that included fetal deaths, and our results were not different.

${ }^{7}$ Sex ratios among twins are generally very close to one. While singleton births are more likely to be male than female (there are approximately 105.1 boys born for every 100 girls born), twin births appear to be approximately equally likely to be male as female (NCHS 1992). Further, this sex ratio for twins appears to have remained constant for almost a century. Weinberg posited in 1902 that twins face an almost equal possibility of being male as being female, and national data from 1988 further support this hypothesis by presenting a sex ratio for twin births of 100.6 (about 4.5 percent lower than the sex ratio for singleton births) (NCHS 1992). The sex ratio associated with our 1995 through 1997 data - 100.8 - is consistent with these earlier data (see Table 1).
} 
consequently the number of identical twins can be calculated from the number of opposite-sex twins. Weinberg's rule begins with the observation that opposite-sex twins must be fraternal, while same-sex twins may be either identical or fraternal. The goal then is to isolate the portion of same-sex twins that are identical. Because, according to Weinberg's assumptions, twins are equally likely to be male as to be female, the number of opposite-sex twins (who are all necessarily fraternal) must equal the number of fraternal same-sex twins. To isolate the identical twins in the same-sex twin group one, then, simply subtracts the number of opposite-sex twins from the number of same-sex twins. The difference is then the number of identical twins. Borrowing an example from Coney and Mackey's (1996) review of the Weinberg rule, if one had 100 twin pairs, 30 of which were opposite sex and 70 of which were same-sex, we could assume that 30 of the same-sex pairs were fraternal and, consequently 40 of the same-sex pairs were identical.

We have a total sample size of 271,998 . Of this total, 91,440 twins are part of a mixed sex pair and 180,558 are part of a same sex pair. We know that all mixed sex twin pairs are fraternal (so, 91,440 members of our sample are definitely fraternal), and we would expect, based on evidence of twins' sex ratios (approximately 100), that an equal number fraternal twins are part of same sex pairs as are part of mixed sex pairs. We would, therefore, expect that 91,440 of the 180,558 members of same sex pairs in our sample would be fraternal. Taking 91,440 from 180,558 , we are left with 89,118 individuals that should be part of identical twin pairs.

Another way to consider this deduction of zygosity as it relates to the estimation of birth weight effects is to note that if:

- $\quad \mathrm{a}=$ effect of birth weight for fraternals

- $\quad b=$ effect of weight for identicals (this is our unknown entity) 
- $\mathrm{c}=$ effect of weight for same sex group, and

- $\mathrm{p}=$ the fraction of identical twins in the same sex group

then we can treat $c$ as a weighted average of $a$ and $b$ :

$$
c=b p+a(1-p)
$$

Since we know c, a, and p, we can solve for b:

$$
b=\frac{c-a(1-p)}{p}
$$

Standard errors can then be estimated based on the following:

$$
\operatorname{Var}(b)=\operatorname{Var}(c)(1 / p)^{2}+\operatorname{Var}(a)((1-p) / p)^{2} \quad \text { as long as } \operatorname{Cov}(a, c)=0^{8}
$$

It should be noted that Weinberg's rule is not the ideal method for determining the zygosity of twins. Testing of genetic markers remains the gold standard for determining whether twins are identical or fraternal. Zygosity information based on such a method though is generally not available to researchers working with nationally representative samples or populations. As an alternative, the Weinberg rule has been rather widely accepted as a method for determining zygosity in large datasets. Over the past several decades many researchers have tested the validity of the Weinberg rule by comparing result gained with the Weinberg rule to results gained from genetic testing and examination of placental membranes (Cannings, 1969; Coney and Macky, 1996; Husby et al. 1991; James, 1992; Vlietinck et al. 1988). The results of these validity tests have not been completely consistent. Most tests found similar results across the

\footnotetext{
${ }^{8}$ This assumption is equivalent to saying that the error terms for the parameter estimate for fraternals and identicals are not correlated. Even if they are systematically biased in the same direction, then our imputed standard error is larger than it need be, so this assumption is conservative. If they happen to be biased systematically in opposite directions, then we are underestimating the error. Aside from chorionicity issues, most of the potentially biasing factors (like shared maternal resources, maternal behavioral during pregnancy, space-growth limitations, prematurity and so on) are all biased in the same direction for fraternals and identicals.
} 
different methods, but a few tests found that genetic tests and placental analysis reveal more same-sex fraternal twins than opposite sex fraternal twins (see, for instance, Coney and Macky, 1996 and James, 1979). These differences were generally found in studies with smaller samples and, overall, such differences between frequencies of opposite and same-sex fraternal twins were slight. Nonetheless, such a pattern suggests that the Weinberg rule may overestimate the number of identical twins. If this pattern is true, such overestimation of identical twins would result in our underestimating the differences between identicals and fraternals. As outlined in the above equations, we will treat the coefficients of our mixed sex subsample as an average of the birth weight effects for both identical twins and fraternal twins, and will then use this observed estimate to solve for the two separate estimates for the identical and fraternal groups. This implies that, if the number of identical twins is smaller than we estimate, the difference between identical and fraternal coefficients must be larger than that which we estimate. That is, any bias in this study would lead to an underestimation of the role of genetics in birth weight and infant mortality.

There is an additional issue though, which has become salient only very recently, that may affect the validity of the Weinberg rule. In the brief time period from 1980 to 1997, the twin birth rate in the United States increased from 18.9 per 1000 live births to 26.8 per 1000 live births (Martin and Park 1999). Most evidence suggests that this pattern is the result of a sharp increase in delayed childbearing and the use of fertility treatments. In order for Weinberg's assumptions to still hold, these factors would have to lead to an equal increases in both identical and fraternal twinning. Evidence drawn from fertility clinics in several nations offer very mixed evidence on this question. While some studies suggest that fertility treatments are associated with an increase in identical twinning, other studies find no such association (Schachter et al. 2001; 
Sills et al. 2000; Platt et al. 2001; Kyvik et al. 1995; Imaizumi and Nonaka, 1997; Imaizumi, 1999). If, because of recent trends in multiple births, our assumptions about the distribution of identical and fraternal twins are inaccurate, it is probably the case that we have overestimated the number of identicals as compared to fraternals. As explained above, such error, if existing on a significant level, would imply that our estimates of the differences between fraternal and identical twins would be underestimated.

The issue of monochorionic and dichorionic twins may also confound our efforts to accurately estimate the effects of birth weight on mortality by zygosity. To the extent that part of the differences in birth weight effects across identical and fraternal twins is the result of chorionicity rather than zygosity our assumption of zygosity differences will be compromised. Ambiguity over chorionicity, however, is an issue that many studies using large representative samples face (see, e.g., West et al. 1999 and Hollier et al. 1999). It can be somewhat difficult to determine chorionicity in identical twins so such information is rarely available on a wide scale. Chorionicity can only be assessed by an ultrasound in the first trimester or early in the second trimester of a pregnancy, which means that if the first ultrasound is not done during this time period it will be very difficult or impossible to ascertain chorionicity (Dube et al. 2002; Devlieger et al. 2001). As a cautionary note, the effect of chorionicity in this study would likely lead us to find a larger effect of birth weight among identicals as compared to fraternals. In other words, it should cause us to find stronger birth weight effects among those that are genetically similar, and would therefore cause us to lower our estimates of underlying genetic effects.

In our analysis we find no significant interactions between birth weight and sex. In the mixed sex sub-sample the interaction term for birth weight by sex is not statistically significant, and we further find no difference in birth weight parameters across our boy-only or girl-only 
sub-samples. This lack of an interaction between birth weight and sex allows us to assume that differences in birth weight parameters between our same sex and mixed sex sub-samples are not due to sex differences, but rather are due to differences in zygosity. (This approach also requires the assumption that the probability of death is the same for all sub-samples. This is true by definition in our sample since in order to make it into the analysis, one twin has to live and one twin has to die in the relevant time frame. Thus, each twin set in this analysis has a probability of death of 50 percent.) These assumptions about genetic variation then allows us to sort out "true" birth weight effects from situations in birth weight effects are a proxy for alternative underlying genetic conditions.

\section{Variables}

Birth Weight. The birth weight of each twin is a continuous variable measured in pounds (with decimal points). The birth weight variable was originally coded in ounces and we simply divided by 16 to convert to pounds. This implies that discordance in birth weight between twins is treated simply as the birth weight of the first twin (in pounds with decimal points) minus the birth weight of the second twin (in pounds with decimal points). Here, we are assuming that the impact of birth weight is linear. Alternative specifications that were tested included logged birth weight and a series of dummy variables. However, around the relatively low birth weight range of our twin sample, a linear specification provided the best fit.

First Born. All individuals who were the first child born within the twin set are given a one, while all children born second within the twin set are given a zero. It is necessary to control for first born status in multiple birth sets because evidence suggests that second born twins are at 
higher risk, compared to first born twins, for various health complications and for neonatal mortality (Webb and Shaw 2001; Imaizumi 2001).

Female. A dichotomous variable in which all females are given a one and all males a zero is included in this analysis because research has shown that the entire birth weight distribution of females is shifted to the left of that of males, and thus, females have a greater risk of being born at low birth weight than males (Gross et al. 1997). At the same time, however (perhaps because of the shift in the female birth weight distribution), low birth weight females have been shown to suffer fewer of the health and developmental problems associated with low birth weight (for a summary, please see Bennett 1997). Thus, the role of low birth weight in infant mortality may vary depending on sex; however, as mentioned previously and as shown in the results section, this does not appear to be the case in this analysis of twin births.

Infant Mortality, Neonatal Mortality, Post-neonatal Mortality. We use three different measures of mortality. First, we use overall infant mortality, which is defined as death under one year of age, as an outcome measure. However, we also decompose this measure into neonatal mortality (death under 28 days of age) and post-neonatal mortality (between 28 days and one year) as subsequent outcome measures (Hoyert et al. 2001). Breaking down measures of infant mortality in this way reveals striking differences in causes of death. Disorders related to short gestation and low birth weight are the primary cause of neonatal infant death, while Sudden Infant Death Syndrome is the primary cause of post-neonatal infant death (Anderson 2001). More importantly in this analysis, however, is the fact that these two time frames allow us to examine whether effects of birth weight are more or less genetically spurious as time passes. 


\section{RESULTS}

Turning to Figure 1 (which is based on the coefficients from Table 2 and Table A1), we can see the results of our analysis of infant mortality among twins. Overall, a twin who is a pound lighter than his/her sibling is about 18.7 percent more likely to die in the first year of life. ${ }^{9}$ We can immediately note that our results contradict those reported by Almond, Chay, and Lee (2003). Almond, Chay, and Lee, using a single year (1989) of matched Vital Statistics data, find that twin estimates yield no effect of birth weight on infant mortality. (Perhaps differences in our results can be attributed to the different years of data with which we work; beyond this, we are at a loss to account for the differences.)

When we break that out into same sex and opposite sex pairs, we find that the effect for same sex pairs is weaker than for opposite sex pairs, a difference in parameter estimates that is statistically significant $(\mathrm{t}=2.451)$. (The coefficients for the girls-only and boys-only sub-

\footnotetext{
${ }^{9}$ All percentage changes in the probability of death resulting from a difference in birth weight (presented in the figures) are calculated with the following three steps:

(1) Finding the change in the log-odds ratio resulting from a one-unit change in birth weight (net of control variables):

Eq. $1 \quad\left[\log \left(\mathrm{p}_{1} / 1-\mathrm{p}_{1}\right)\right]=\beta_{0}+\beta_{1}\left(\mathrm{X}_{1}+.5\right)+\beta_{2} \mathrm{X}_{2}+\beta_{3} \mathrm{X}_{3}$ and

Eq. $2\left[\log \left(\mathrm{p}_{2} / 1-\mathrm{p}_{2}\right)\right]=\beta_{0}+\beta_{1}\left(\mathrm{X}_{1}-.5\right)+\beta_{2} \mathrm{X}_{2}+\beta_{3} \mathrm{X}_{3}$,

where $\mathrm{X}_{1}=$ mean birth weight, $\mathrm{X}_{2}=$ mean (proportion) first born status, and $\mathrm{X}_{3}=$ mean (proportion) female.

(2) Translating the log-odds ratio into a probability of death:

$$
\begin{array}{ll}
\text { Eq. } 3 & \mathrm{p}_{1}=\left[\exp \left(\beta_{0}+\beta_{1}\left(\mathrm{X}_{1}+.5\right)+\beta_{2} \mathrm{X}_{2}+\beta_{3} \mathrm{X}_{3}\right)\right] /\left[1+\exp \left(\beta_{0}+\beta_{1}\left(\mathrm{X}_{1}+.5\right)+\beta_{2} \mathrm{X}_{2}+\beta_{3} \mathrm{X}_{3}\right)\right] \\
\text { Eq. } 4 & \mathrm{p}_{2}=\left[\exp \left(\beta_{0}+\beta_{1}\left(\mathrm{X}_{1}-.5\right)+\beta_{2} \mathrm{X}_{2}+\beta_{3} \mathrm{X}_{3}\right)\right] /\left[1+\exp \left(\beta_{0}+\beta_{1}\left(\mathrm{X}_{1}-.5\right)+\beta_{2} \mathrm{X}_{2}+\beta_{3} \mathrm{X}_{3}\right)\right]
\end{array}
$$

(3) Finding percentage change in the probability of death due to a one-pound decrease in birth weight about the mean:
} 
samples that comprise the total same-sex subsample in Table 2 are not statistically different.) Following our assumption that 50 percent of same sex twin pairs are identical, we know that the coefficient for same sex twins is an average of that for fraternal and identical twins. And we know that the mixed sex sample is all fraternal. Since we also find no significant gender differences in the effects of birth weight in the mixed sex pairs or when we split the same sex sample into boys and girls (see Table 1), we can be confident that the difference in the effect of birth weight among same sex and opposite sex twin sets is a result of zygosity (and possibly choronicity) differences. With this in mind, we can infer the effect of a pound of weight for the identical twin subsample. While the effect for fraternals is such that a twin who is a pound lighter than its sibling is 22.3 percent more likely to die in the first year of life, the inferred effect for identicals, suggests that one less pound of weight increases the risks of death by 12.8 percent (see Table A1 of Appendix A for the coefficient this percentage change is based on). These results indicate that any of the more severe conditions associated with monochorionicity are probably overshadowed by the fact that among fraternals, birth weight may be acting as a proxy for other underlying congenital health conditions, which leads to the excess strength of the estimate for this group as compared to the identical twin subset.

\section{[FIGURE ONE ABOUT HERE]}

\section{[TABLE TWO ABOUT HERE]}

In order to better understand the pattern of effects here, we break out this analysis into neonatal and post-neonatal mortality. In Figure 2 (which is based on the coefficients from Table 3), we see that in predicting death in the first month of life, birth weight matters significantly. However, the effect for fraternal twins is much greater than that which we infer for identical twins - a difference that is more pronounced than that for overall infant mortality. A one-pound 
difference in weight between fraternal twins results in a 27.4 percent difference in the probability of neonatal death. However, a one-pound difference in weight between identical twins results in a difference of 10.9 percent in the risk of neonatal death. This would seem to indicate that to a certain extent birth weight is acting as a proxy for other underlying genetic conditions (which vary between fraternal twins and do not vary between identical twins) that make their impact felt strongly in the first month of life.

\section{[FIGURE TWO ABOUT HERE]}

\section{[TABLE THREE ABOUT HERE]}

This stands in contrast to the effects presented in Figure 3 (which are based on the coefficients in Table 4), where the impact of "poundage" is the same for fraternal and identical twin sets. In predicting post-neonatal mortality (conditional on living past day 28 of life), it appears as though each additional pound results in about a 14 percent decrease in the chance of death-for both identical and fraternal twins.

\section{[FIGURE THREE ABOUT HERE]}

\section{[TABLE FOUR ABOUT HERE]}

\section{DISCUSSION}

Our comparisons of birth weight effects across identical and fraternal twins suggest that after an initial weeding-out process where the more sever conditions associated with genetic differences may be behind birth weight effects, birth weight per se does indeed appear to have an impact on life chances net of genes. Birth weight appears to have a 9.5 percentage point stronger effect for fraternal twins than for identical twins in the neonatal period (while fraternal twins experienced a 22.3 percent increase in risk with the loss of one pound, identical twins experienced only a 12.8 percent increase from a comparable loss during this early period). This 
result implies that genetic conditions underlying birth weight, which are likely associated with more serious health risks, may be playing a stronger role than fetal growth (net of its genetic roots) in early risk of infant mortality. However, birth weight appears to have approximately equal effects for fraternal and identical twins in the post-neonatal period (both fraternal and identical twins experienced a 14 percent decrease in the chance of death with a one-pound increase). Alternatively, this suggests that fetal growth, per se, plays a larger role than associated genetic conditions in later risks of infant morality.

Twin pairs, because of their similar prenatal situations, and in certain cases their identical genes, present researchers with a unique opportunity to make stronger causal statements than are usually possible with non-twin populations. The flip side of this opportunity, however, is a possible loss in the generalizability of results. A consistent question one encounters with twin analyses is whether results can be applied to non-twin populations. The effect of birth weight on infant mortality in singleton populations generally proceeds in a relatively steep incremental fashion until one reaches weights above approximately 2500 grams. ${ }^{10}$ At these higher weights, the effect of birth weight significantly decreases and does not change notably as birth weights continue to rise. In other words, up through the 2500-gram cut-off (the range in which most of our twins are found) the effect of birth weight on infant mortality is strong and roughly linear, however once one passes this area of the distribution, the pattern flattens out. The linear effect of birth weight we document in this study of twins suggests that the association between birth weight and mortality found among twins approximates the association found among smaller singleton births, but not necessarily the association found among larger singleton births. Such a limitation is not terribly surprising given that twins generally fall at the lower end of the birth weight distribution. 
To the degree our results can be extended over time, it would seem that birth weight — or, more specifically, fetal growth — may have its own direct effect on adult (socio-economic) outcomes, net of underlying genetic tendencies or pregnancy specific conditions. As we discussed above, across-family comparisons and sibling comparisons that examine the association between birth weight and adult outcomes generally cannot make strong causal statements about birth weight effects since the underlying causes of low birth weight may also be causally implicated in later outcomes. Here we have shown, however, that after holding constant underlying factors (such as genetics and preterm birth) low birth weight — as a specific result of fetal growth — may be become increasingly important as children age. Extending the logic of these results outward 19 years, it seems that the long-term consequences of low birth weight documented by Conley and Bennett (2000, 2001) and Behrman and Rosenzweig (2001), respectively, likely reflect, to a substantial degree, "true" effects of fetal growth. While we cannot assume that any early genetic "weeding out" process associated with infant mortality proceeds in a consistent fashion across the life course, or is directly applicable to educational attainment, it does seem that birth weight has its own effect on "life chances," and does not only reflect unobserved genetic or pregnancy-specific conditions.

This debate aside, however, our results further suggest the importance of attention to fetal growth in efforts to improve infant health. Infant mortality rates are frequently considered to be an important indicator of social well-being, and several existing policy efforts aim at lowering infants' risk of death. Here we have shown that infant mortality is highly sensitive to rates of fetal growth, and hence provide one further piece of evidence to underpin the importance of improving rates of fetal growth in the effort to reduce infant mortality. More specifically, further

\footnotetext{
${ }^{10}$ See Almond, Chay, and Lee (2002) for a review of these patterns.
} 
attention may need to be paid to nutrition education and supplementation in prenatal programs in the developed world and to food distribution in developing countries.

An increasing amount of attention has been paid as of late to the roles of prenatal and early life conditions in adult outcomes. Indeed, it seems that the determinants of adult success are being increasingly pushed back to infancy and even the previous generation. However, with such models that span life times and generations, the relative contributions and interactions between various factors — such as biology, genetics, and society—become increasingly complex and difficult to sort out. The etiologies behind early-life conditions can be difficult to isolate, ultimately making it impossible to say why early-life conditions matter in the long run. In this study, we have begun to speak to this problem by using twin comparisons to isolate the effects of fetal growth, pregnancy conditions, and genetics on infant mortality. 


\section{References}

Almond, D.; Chay, K.; Lee, D. (2002) "Does Low Birth Weight Matter? Evidence from the U.S. Population of Twin Births." Working Paper No. 53. Center for Labor Economics, University of California, Berkeley.

Anderson, R. (2001) "Deaths: Leadings Causes for 1999" National Vital Statistics Report 49 (11). Division of Vital Statistics: Centers for Disease Control. HTLM Document Available at http://www.cdc.gov/nchs/data/nvsr/nvsr49/nvsr49_11.pdf

Ashenfleter, O.; Kreuger, A. (1994) "Estimates of the Economic Returns to Schooling from a New Sample of Twins." American Economic Review. 84:1157-1173.

Ashenfelter, O.; Rouse, C. (1997) "Income, Schooling, and Ability: Evidence from a New Sample of Identical Twins.” Working Paper 6106. National Bureau of Economic Research, Cambridge, MA.

Behrman, J.; Rosenzweig, M. (2001) “The Returns to Increasing Body Weight.” Working Paper No. 01-052. Penn Institute for Economic Research, University of Pennsylvania. URL Document available at http://www.econ.upenn.edu/pier/year1.html\#2001

Bennett, F. (1997) "The LBW, Premature Infant” in Gross, R.; Spiker, D.; Haynes, C. (eds.) Helping Low Birth Weight, Premature Babies: The Infant Health and Development Program. Stanford, CA: Stanford University Press: 3-16.

Bound, J.; Solon, G. (1998) "Double Trouble: On the Value of Twins-Based Estimates of the Returns to Schooling.” Working Paper 6721. National Bureau of Economic Research, Cambridge, MA.

Bortolus, R.; Parazzini, F.; Chatenoud, L.; Benzi, G.; Bianchi, M.; Marini, A. (1999) “The Epidemiology of Multiple Births.” Human Reproduction Update. 5(2): 179-187.

Cannings, C. (1969). “A Discussion of Weinberg's Rule on the Zygosity of Twins.” Annals of Human Genetics. 32: 403-405.

Cheung, V.; Bocking, A.; Dasilva, O. (1995) "Preterm Discordant Twins: What Birth Weight is Significant?" American Journal of Obstetric Gynecology. 172(3): 955-9.

Coney, N.; Mackey, W. (1996) “Weinberg's rule versus Facultative Sex Ratio: An Impasse in Need of Occam's Razor.” The Mandkind Quarterly. 37(2): 187-201.

Conley, D.; Bennett, N. (2001) "Birthweight and Income: Interactions Across Generations." Journal of Health and Social Behavior. 42(4): 450-465.

Conley, D.; Bennett, N. (2000) “Does Biology Determine Life Chances?” American Sociological Review. 63(3): 458-467. 
Devlieger, R.; Demeyere, T.; Deprest, J.; Schoubroeck, D.; Witters, I.; Timmerman, D.; Hanssens, M. (2001) "Ultrasound Determination of Chorionicity in Twin Pregnancy: Accuracy and Operator Experience." Twin Research. 4(4): 223-226.

Dube, J.; Dodds, L.; Armson, B. (2002) "Does Chorionicity or Zygosity Predict Adverse Perinatal Outcomes in Twins?" American Journal of Obstetrics and Gynecology. 186(3): 579-83.

Fraser, D.; Picard, R.; Picard, E.; Leiberman, J. (1994) “Birth Weight Discordance, Interuterine Growth Retardation and Perinatal Outcomes in Twins." Journal of Reproductive Medicine.39(7):504-8.

Frisbie, W.; Forbes, D.; Pullman, S. (1996) "Comprimised Birth Outcomes and Infant Mortality Among Racial and Ethnic Groups.” Demography. 33(4):469-481.

Gross, R.; Spiker, D.; Haynes, C. (eds.) (1997) Helping Low Birth Weight, Premature Babies: The Infant Health and Development Program. Stanford, CA: Stanford University Press:

Hack, M.; Flannery, D.; Schluchter, M.; Cartar, L.; Borawski, E.; Klein, N. (2002) "Outcomes in Young Adulthood for Very Low Birth Weight Infants." The New England Journal of Medicine. 346(2): 149-157.

Hollier, L.; McIntire, D.; Leveno, K. (1999) “Outcome of Twin Pregnancies According to Interpair Birth Weight Differences.” Obstetrics and Gynecology. 94(6):1006-1010

Hoyert, D.; Arias, E.; Smith, B.; Murphy, S.; Kochanek, K. (2001) "Deaths: Final Data for 1999." National Vital Statistics Report 49 (8). Division of Vital Statistics: Centers for Disease Control. HTLM Document Available at http://www.cdc.gov/nchs/data/nvsr/nvsr49/nvsr49_08.pdf

Husby, H.; Holm, N.; Gernow, A.; Thomsen, S.; Gurtler, H. (1991). "Zygosity, Placental Membranes and Weinberg's Rule in a Danish Consecutive Twin Series." Acta Geneticae Medicae et Gemellologiae. 40: 147-152.

Imaizumi, Y. (1999) "Constant Multiple Birth Rates in the Czech Republic and the Slovak Republic Until Recently, 1972-1995.” Twin Research. 2(1): 10-15.

Imaizumi, Y. (2001) "Infant Mortality Rates in Single, Twin and Triplet Births , and Influencing Factors in Japan, 1995-1998." Pediatric and Perinatal Epidemiology. 15: 346-351.

Imaizumi, Y.; Nonaka, K. (1997) “The Twinning Rates by Zygosity in Japan, 1974-1994.” Acta Genetica Medical Gemellola. 46(1): 9-22.

James, W. (1992). “The Current Status of Weinberg's Differential Rule." Acta Geneticae Medicae et Gemellologiae. 41: 33-42. 
James, W. (1979). “Is the Weinberg Rule Valid?" Acta Geneticae Medicae et Gemellologiae. 28: 69-71.

Kallan, J. (1993) "Race, Intervening Variables, and Two Components of Low Birth Weight." Demography.30(3): 489-506.

Kawachi, I.; Kennedy, B.; Wilkinson, R. (1999) The Society and Population Health Reader: Income Inequality and Health. New York: The New Press.

Kramer, M.; Platt, R.; Yang, H.; McNamara, H.; Usher, R. (1999) “Are All Growth-restricted Newborns Created Equal(ly)?” Pediatrics. 103(3): 599-602.;

Kyvik, K.; Beck-Nielsen, H. (1995) "The New Danish Twin Register: Establishment and Analysis of Twinning Rates." International Journal of Epidemiology. 24: 589-596.

Martin, J.; Park, M. (1999) “Trends in Twin and Triplet Births: 1980-97” National Vital Statistics Report. 47(24) National Center for Health Statistics, U.S. Department of Health and Human Services.

Martin, J.; Curtin, S.; Saulnier, M.; Mousavi, J. (1998) "The Matched Multiple Birth File.” National Center for Health Statistics: Centers for Disease Control. HTLM Document Available at ftp://ftp.cdc.gov/pub/Health_Statistics/NCHS/datasets/mmb/

National Center for Health Statistics (NCHS) (1992) "Health and Demographic Characteristics of Twin Births: United States, 1988." Vital and Health Statistics. Series 21: Data on Natality, Marriage, and Divorce. No. 50. (DHHS Publication No. (PHS) 92-1928) Hyattsville, MA: U.S. Department of Health and Human Services.

National Center for Health Statistics (NCHS) "Multiple Birth Rate for Older Women is Sky Rocketing." News Release. September 14, 1999. HTLM Document Available at http://www.cdc.gov/nchs/releases/99facts/multiple.htm

National Center for Health Statistics (NCHS) "Table 1. Number of matched, unmatched, and incomplete records of twins and triplets by perinatal outcome: United States, 1995-1997." HTLM Document Available at ftp://ftp.cdc.gov/pub/Health_Statistics/NCHS/datasets/mmb/

Platt, M.; Marshall, A.; Pharoah, P. (2001) "The Effects of Assisted Reproduction on the Trends and Zygosity of Multiple Births in England and Wales 1974-99." Twin Research. 4(6): 417-421.

Rich-Edwards, J. (1997) "Birth Weight and Risk of Cardiovascular Disease in a Cohort of Women Followed Up Since 1976.” British Medical Journal. 35:396-400.

Schachter, M.; Raziel, A.; Friedler, S.; Strassburger, D.; Bern, O.; Ron-El, R. (2001)

"Monozygotic Twinning After Assisted Reproductive Techniques: a Phenomenon Independent of Micromanipulation." Human Reproduction. 16(6): 1264-1269. 
Scheper-Hughes, Nancy. 1992. Death Without Weeping : The Violence of Everyday Life in Brazil. Berkeley: University of California Press.

Sills, E.; Moojy, M.; Zaninovic, N.; Veeck, L.; McGee, M.; Palermo, G.; Rosenwaks, Z. (2000) "Human Zona Pellucida Micromanipulation and Monozygotic Twinning Frequency After IVF." Human Reproduction. 15(4): 890-895.

Sorensen, H.; Sabroe, S.; Olsen, J.; Rothman, K.; Gillman, M.; Fischer, P. (1997) "Birth Weight and Cognitive Function in Young Adult Life: Historical Cohort Study." British Medical Journal. 315:401-403.

Talbot, G.; Goldstein, R.; Nesbitt, T.; Johnson, J.; Kay, H. (1997) "Is Size Discordancy an Indication for Delivery of Preterm Twins?" American Journal of Obstetric Gynecology 177(5):1050-4.;

Vlietinck, R.; Derom, C.; Derom, R.; Van den Berghe, H.; Thiery, M. (1988). "The Validity of Weinberg's Rule in the East Flanders Prospective Twin Survey." Acta Geneticae Medicae et Gemellologiae. 37: 137-141.

Webb, R.; Shaw, N. (2001) "Respiratory Distress in Heavier versus Lighter Twins.” Journal of Perinatal Medicine. 29(1):60-3

Weinberg, W. (1902) "Beitrage zur physiologie und pathologie der mehrlingsgebuten beim menschen." Archiv fur die gesamte Psysiologie des Menschen und der Tiere. 88: 346-430.

West, C.; Adi, Y.; Pharoah, P. (1999) "Fetal and Infant Death in Mono- and Dizygotic Twins in England and Wales, 1982-1991." Archive of Diseases in Childhood Fetal and Neonatal Edition. 80:F217-F220.

Yalcin, H.; Zorlu, C.; Lembet, A.; Ozden, S.; Gokmen, O. (1998) "The Significance of Birth Weight Difference in Discordant Twins: a Level to Standardize?" Acta Obstetrica Gyneologica Scandinavia. 77(1):28-31. 


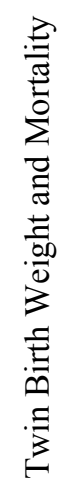

ถี

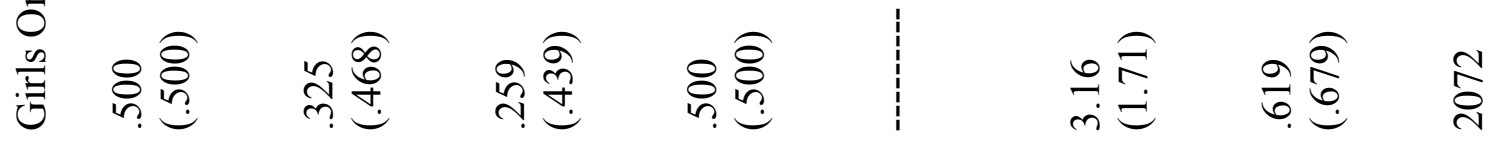

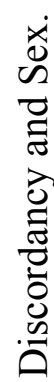

章

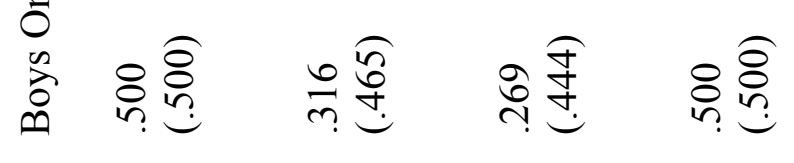

mi̊

ำ

르

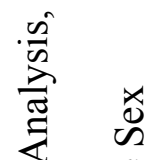

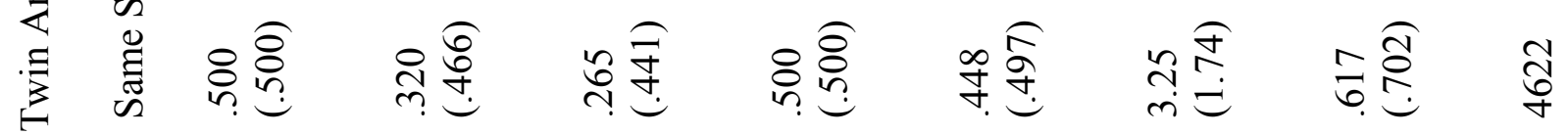

.ョ

D্ర

(8)

爻

룰

กิ

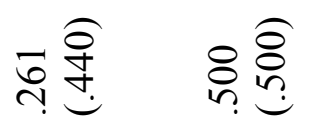

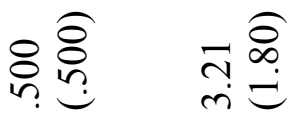

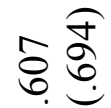

$\frac{N}{2}$

尝

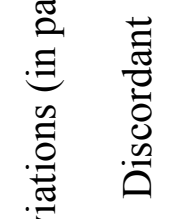

올

तิ

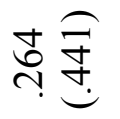

ஓ

ț 守

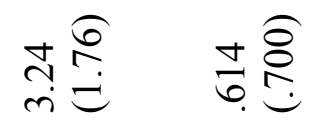

ฐั

䎡

むั

ㅇํㅇํํ

용

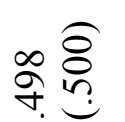

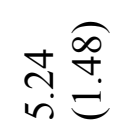

กูర

$\frac{\infty}{2}$

言

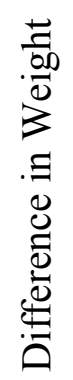

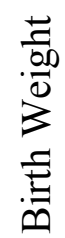

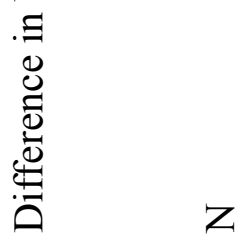




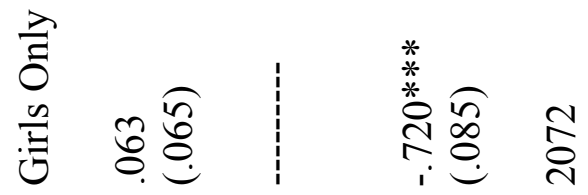

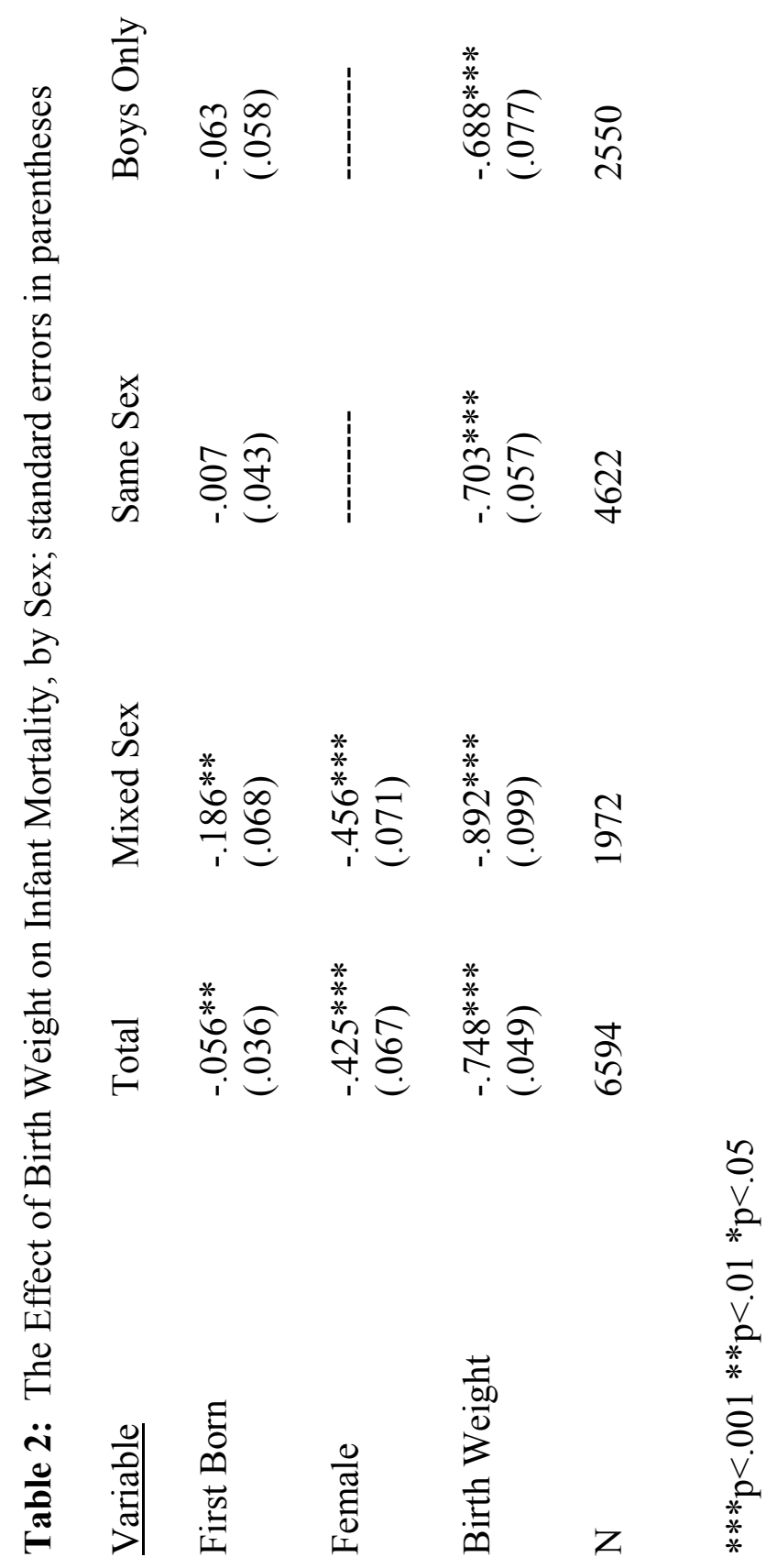




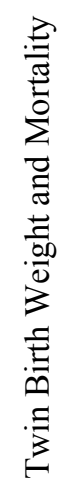

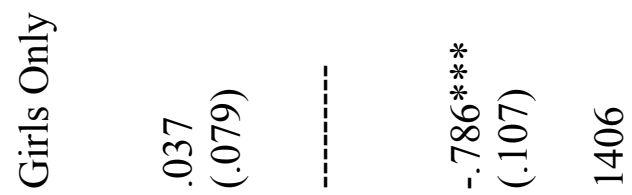

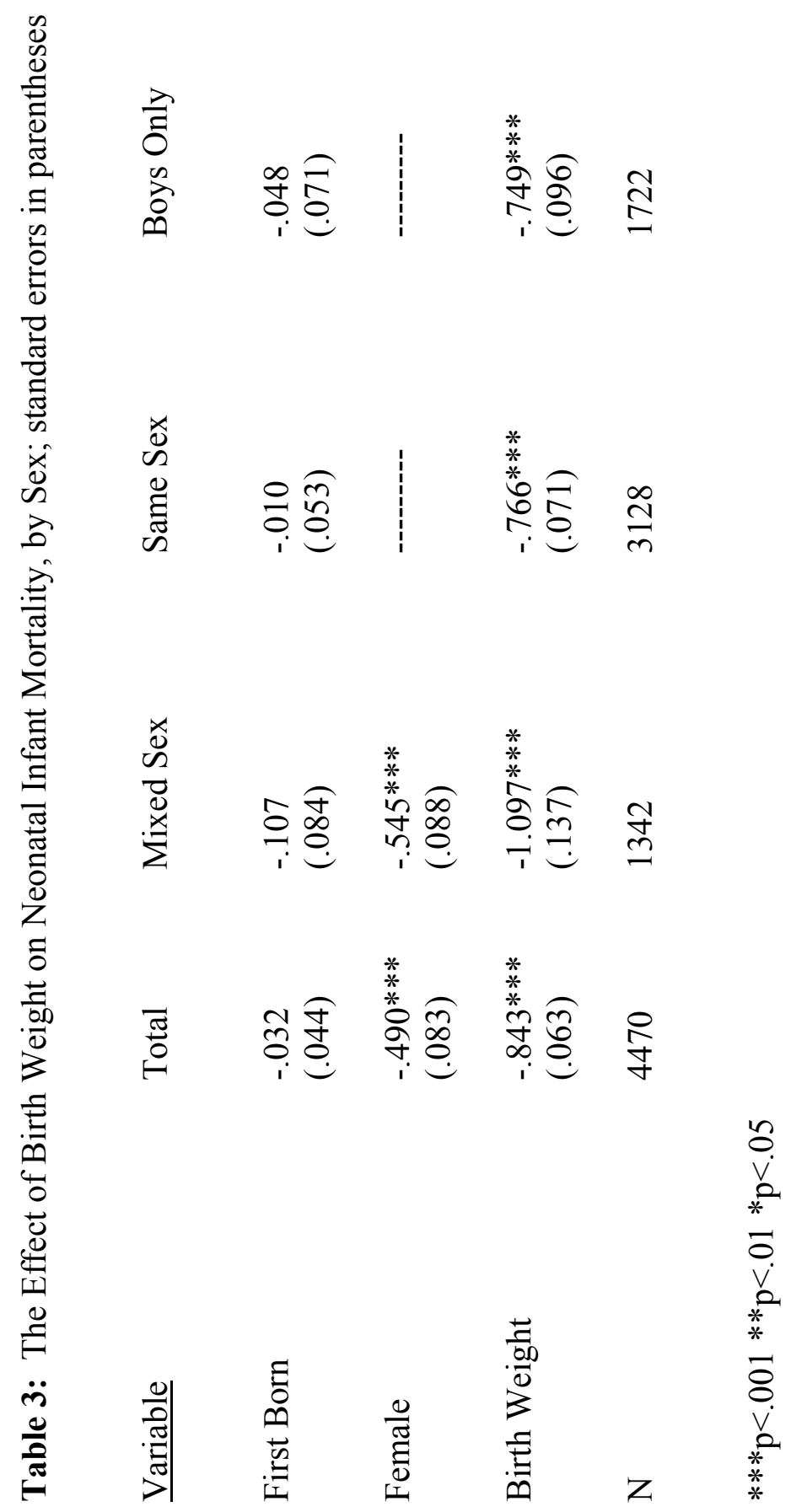




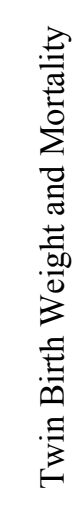

흘

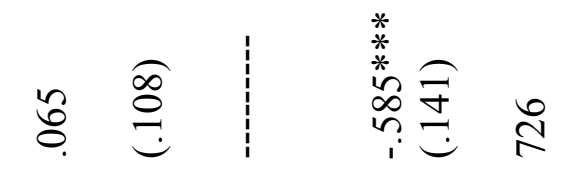

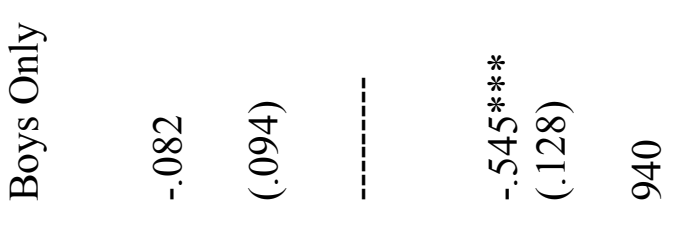

苛



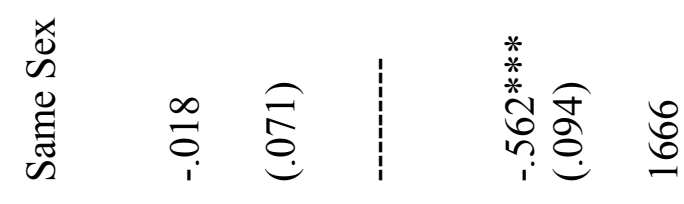

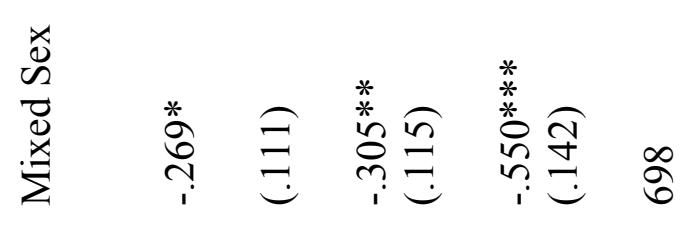

$\stackrel{5}{\frac{7}{0}}$

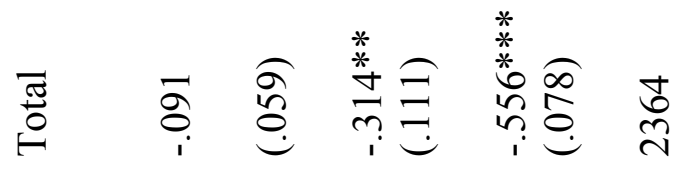

롤

4

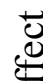

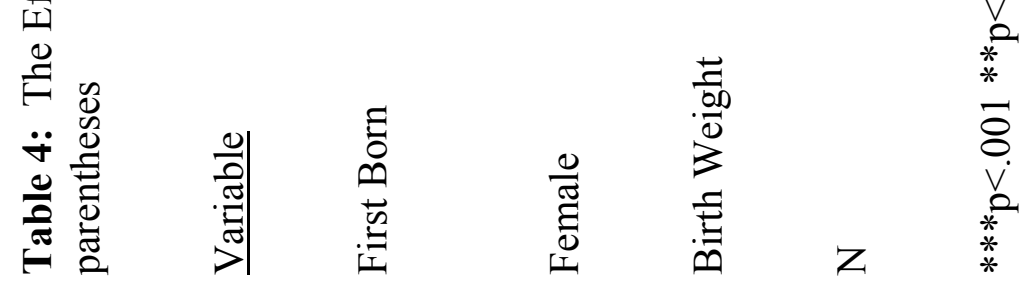



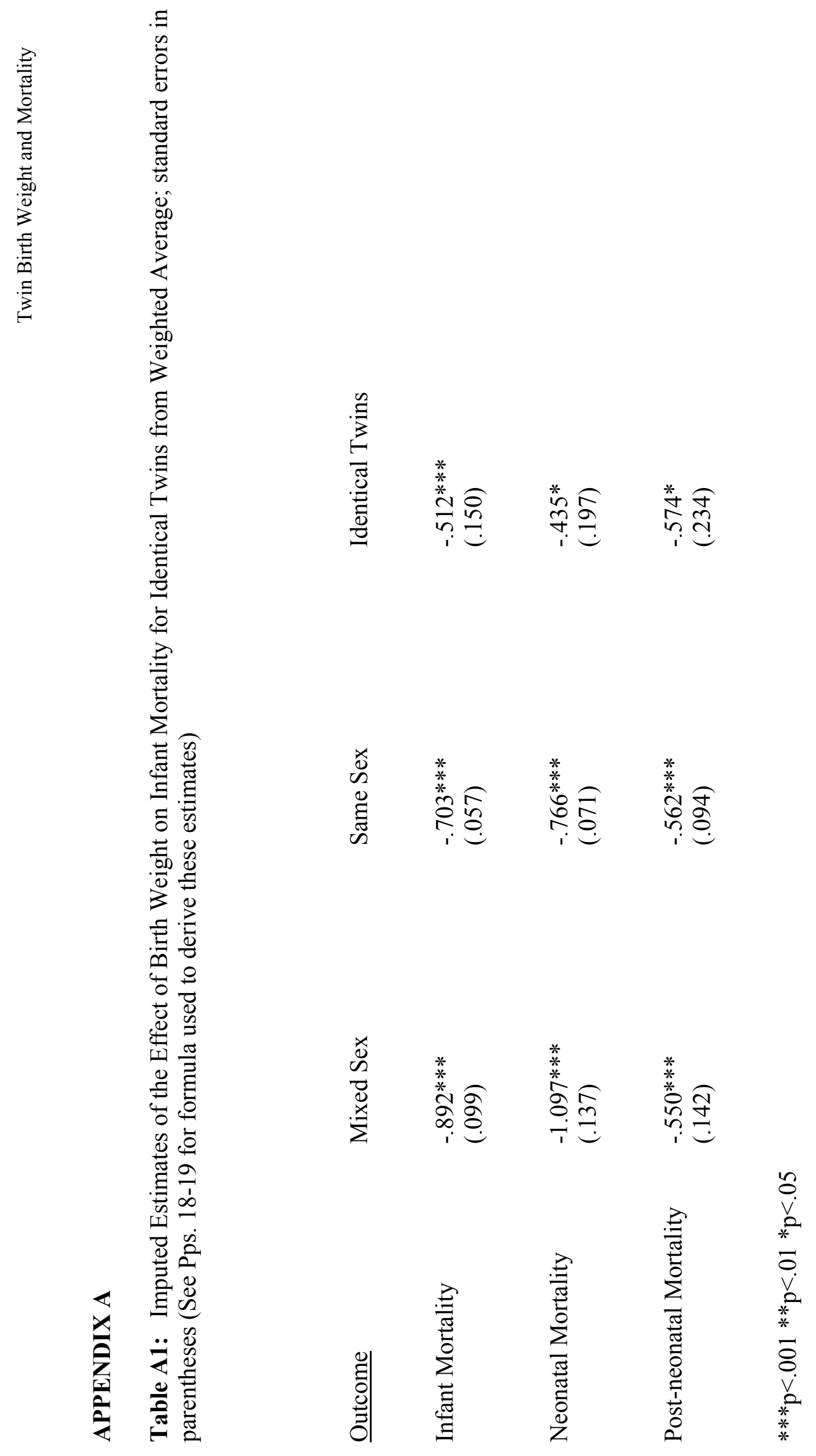
Twin Birth Weight and Mortality

Figure 1: Increased Risk for Infant Mortality by Zygosity for One Pound of Birthweight among Discordant Twin Pairs

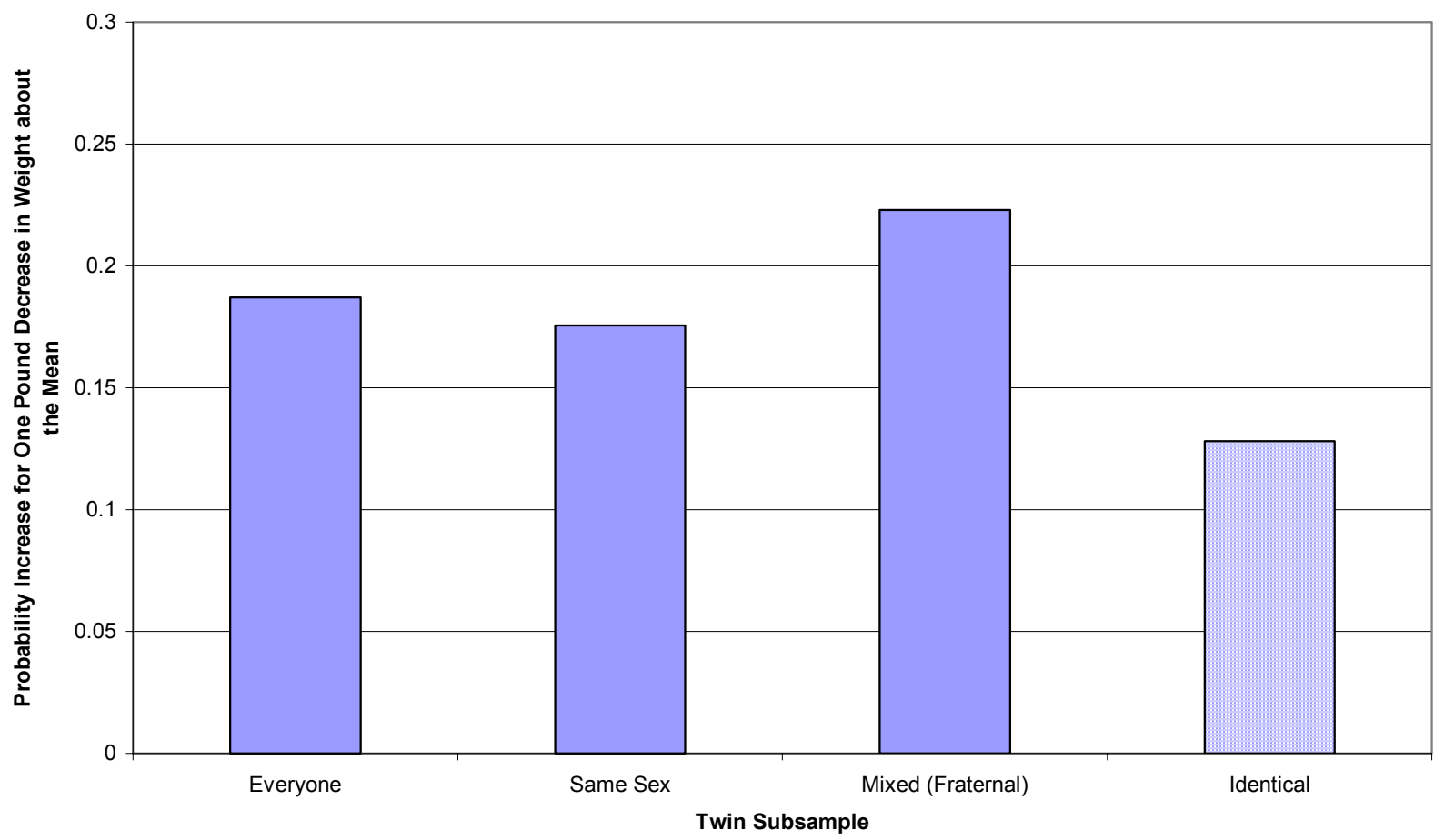


Twin Birth Weight and Mortality

Figure 2: Increased Risk for Neonatal Mortality by Zygosity for One Pound of Birthweight among Discordant Twin Pairs

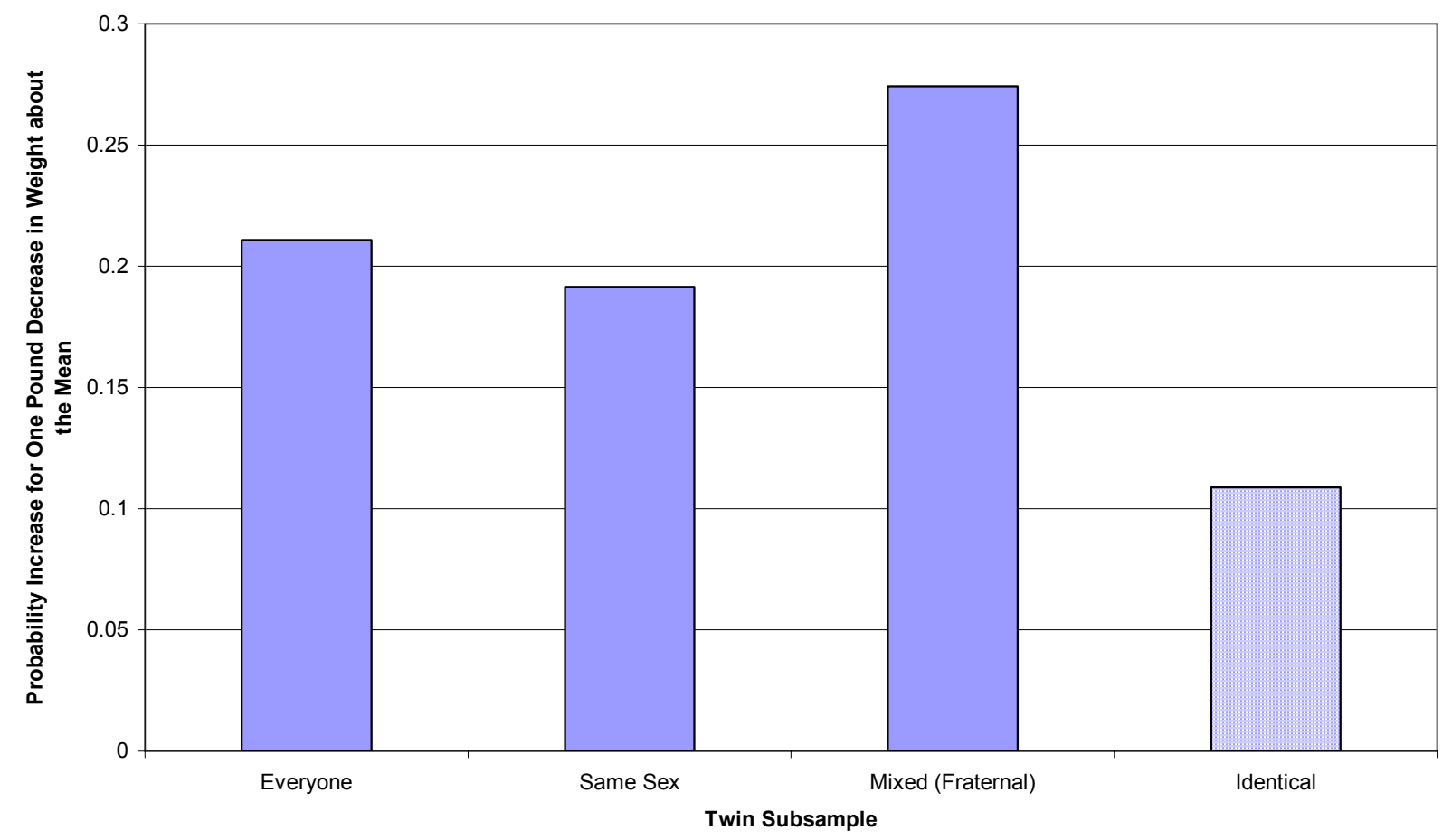


Twin Birth Weight and Mortality

Figure 3: Increased Risk for Post-Neonatal Mortality by Zygosity for One Pound of Birthweight among Discordant Twin Pairs

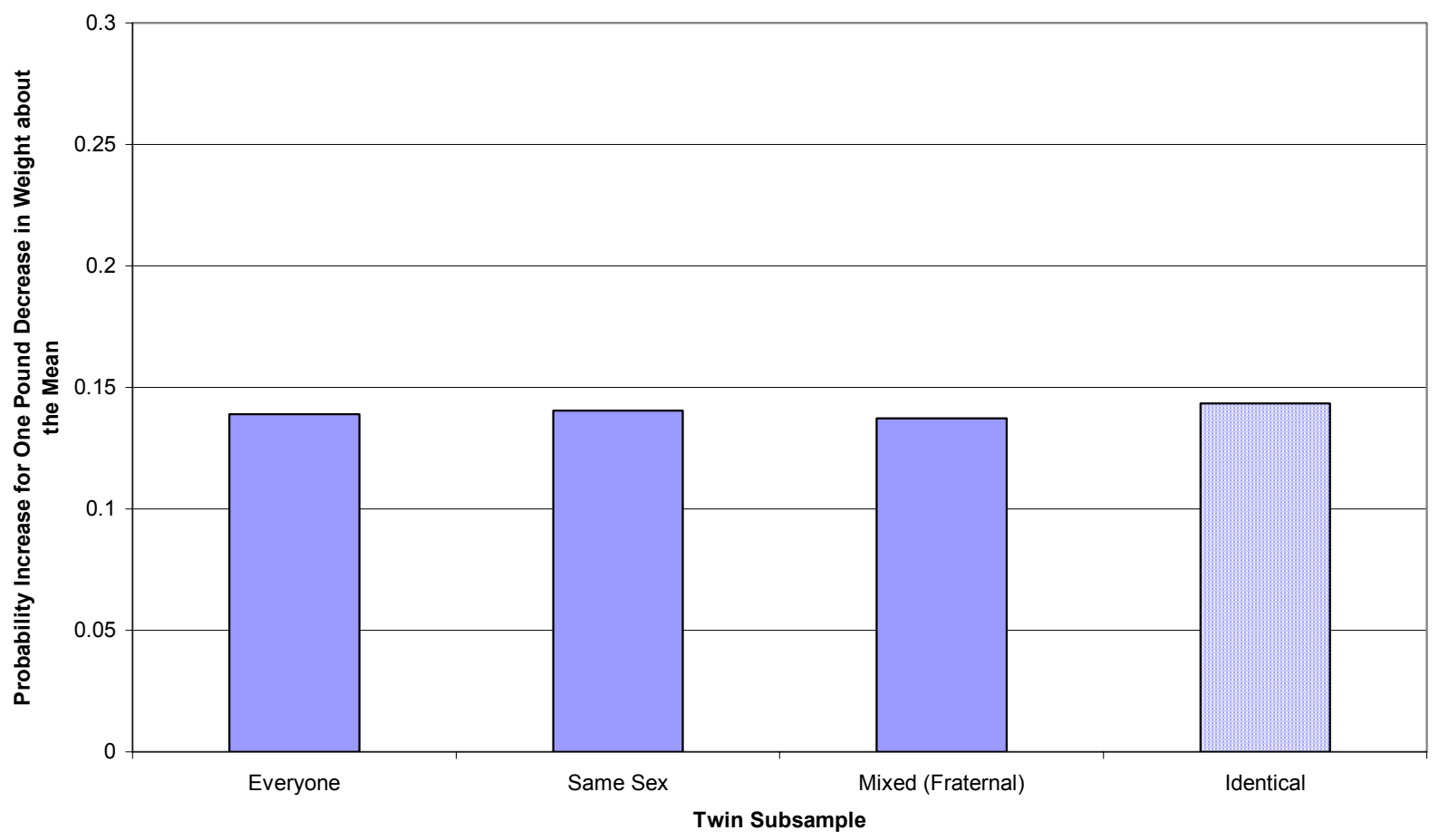

